\title{
Granular Cell Tumour of the Breast Cancer: Challenging Clinical and Radiological Mimic of Cancer
}

\author{
Arnis Abolins*, Ilze Strumfa*/**, Andrejs Vanags***, Genadijs Trofimovics*/***, Janis Gardovskis*/*** \\ *Institute of Oncology, Riga Stradins University, Latvia \\ **Department of Pathology, Riga Stradins University, Latvia \\ ***Department of Surgery, Riga Stradins University, Latvia
}

\begin{abstract}
Summary
Granular cell tumours (GCT) are rare soft tissue neoplasms of unclear histogenesis affecting almost any organ or tissues. Approximately $5 \%$ of GCT cases are located in the breast. Although granular cell tumour is benign in most instances, it can mimic breast cancer by radiological and clinical traits. Increased awareness of GCT is necessary to avoid misinterpretation as cancer and subsequent overtreatment.
\end{abstract}

Key words: breast tumour, granular cell tumour, immunohistochemistry

\section{AIM OF THE DEMONSTRATION}

In order to heighten the awareness of surgeons about the differential diagnosis of breast cancer and about the choice of appropriate extent of surgical treatment, we describe here a rare benign tumour resembling breast cancer clinically and radiologically.

\section{CASE REPORT}

Fifty-six-year-old female consulted doctor with complaints about palpable hard mass in her left breast. The mass was located in upper inner quadrant. By mammography (MG), a spiculated lesion was evident (Fig.1). Core biopsies were obtained under ultrasonography (US) guidance. Biopsy investigation yielded granular cell tumour with invasive growth. Surgical treatment was recommended. Extended sectoral resection with axillary lymph node dissection was performed. The postoperative period was uneventful. On gross examination of the removed breast tissues, there was solid, gray, firm mass, measuring $1.7 \times 1 \times 0.8$ $\mathrm{cm}$. The gross structure suggested invasive growth due to radiating margins. By histology, the tumour was composed of large cells with amphophilic, finely granular cytoplasm, small dark nuclei and thus low nucleo-cytoplasmic ratio. The bland appearance contrasted with marked perineural spread. There was no evidence of peritumoural invasion into lymphatic capillaries or blood vessels. Moderate amount of desmoplastic stroma and few groups of lymphocytes were present as well (Fig.2). By immunohistochemistry, S-100 protein was found in the tumour cell nuclei and cytoplasm (Fig.3). The neoplastic cells did not contain pan-cytokeratin, smooth muscle actin, desmin, estrogen and progesterone receptors, melanosome protein HMB45 and p 53 protein. The proliferation fraction by Ki-67 was low: $1 \%$. The resection margin was free of tumour.
The axillary lymph nodes were free of malignancy (0/7). Thus, the final diagnosis was granular cell tumour with wide invasive growth and perineural spread, without lymph node and resection line involvement. Twelve months later, the patient is free of recurrence.

\section{DISCUSSION}

The history of granular cell tumour classically is associated with Abrikossoff who described granular cell tumour of the tongue in 1926. However, the first hints can be found in the works of Weber, 1854 (Brown et al., 2011). The GCT histogenesis is unclear. Abrikosoff proposed GCT origin from striated muscle cells and therefore named the tumour as myoblastoma. Subsequently, the immunophenotype of GCT with characteristic nuclear and cytoplasmic expression of S-100 protein and lack of myogenic markers (Filipovski et al., 2009) suggested neural origin from Schwann cell. This hypothesis is the most widely accepted nowadays. The granular consistency and large volume of the cytoplasm also is in accordance with the neural origin (Mittal and True, 1988). The GCT cells form intracellular myelin-like invaginations analogous to myelin layers surrounding nerve fibres. The infoldings become autophagocytosed by lysosomes resulting in granular consistency of the cytoplasm. The high number of lysosomes is indirectly confirmed by CD68 positivity.

The development of GCT in breast is known since 1931, when Abrikossoff described such occurrence only 5 years after his first publication of this tumour (Brown et al., 2011). Approximately 5-15\% of GCT cases are located in the breast. GCT prevalence is estimated as 1:1000 in comparison with breast cancer. However, with the development of mammography the prevalence is growing and has reached 1:617 in the screened group and 6.7: 1000 in total population (Brown et al., 2011). 
Thus, at present the problem of GCT is changing from extremely rare tumour to more practical, challenging differential diagnosis of breast cancer. Despite the success of screening, however, review of published cases suggests that until recently, most cases (70\%) were found by palpation (Brown et al., 2011) as in our patient. Clinically GCT can resemble cancer due to firm consistency, nipple and/or skin retraction (Lack et al., 1980; Pergel et al., 2011). These features can be attributed to stromal desmoplasia that was observed in our case as well. Less frequent manifestations include pain, multifocality, colocalisation with ductal carcinoma, tumour fixed to muscles, benign lymphadenopathy including reactive changes (Brown et al., 2011). On mammography, GCT can show several features suggestive of malignancy: irregularity, spiculation, stellation, variable circumscription. However, calcifications are uncommon. US findings include solid heterogeneous poorly defined masses; these masses are hypo-echoic and display posterior shadowing. Thus, both US and MG frequently seems suspicious for malignancy. No radiologic data are specific for GCT. Fine needle aspiration and/or frozen section can be helpful but should be used with the usual caution regarding limits of interpretation. In contrast, the diagnosis in core or excisional biopsy is easy. It can be further justified by IHC. The immunophenotype in the presented case was characteristic. The association with nerve fibres also is in accordance with the described findings (Brown et al., 2011).

The GCT treatment includes wide local excision. Lymph node excision or sentinel lymph node biopsy is not indicated except malignant cases or colocalisation with malignancy. Although conservative approach has been suggested (Patel et al., 2008) it is not accepted. Extensive and/or combined treatment as for breast cancer should be avoided.

The prognosis is favourable. GCT can recur after incomplete resection but even in such cases the course remains benign. Few cases of malignant behaviour are documented (Brown et al., 2011).

In conclusion, granular cell tumour can affect the breast and resemble cancer both clinically and radiologically. Due to benign biological potential and excellent prognosis, surgery should be limited to local excision. Misinterpretation as breast cancer and subsequent overtreatment should be avoided. Correct diagnosis can be reached by core biopsy and immunohistochemical investigation.

\section{Conflict of interest: None}

\section{REFERENCES}

1. Brown AC, Audisio RA, Regitnig P. Granular cell tumour of the breast // Surg Oncol, 2011; 20:97 105

2. Filipovski V, Banev S, Janevska V, Dukova B. Granular cell tumour of the breast: a case report and review of literature // Cases J, 2009; 2:855 1
3. Lack EE, Worsham GF, Callihan MD. Granular cell tumor: a clinicopathologic study of 110 patients // J Surg Oncol, 1980; 13(4):310 - 316

4. Mittal KR, True LD. Origin of granules in granular cell tumour. Intracellular myelin formation with autodigestion // Arch Pathol Lab Med, 1988; 112: $302-303$

5. Patel A, Lefemine V, Yousuf SM, Abou-Samra W. Granular cell tumour of the pectoralis muscle mimicking breast cancer // Cases J, 2008; 6:142

6. Pergel A, Yucel AF, Karaca AS, Aydin I, Sahin DA, Demirbag N. A therapeutic and diagnostic dilemma: granular cell tumour of the breast // Case Rep Med, 2011; doi: 10.1155/2011/972168, 3 pp

\section{ACKNOWLEDGEMENT}

This work was supported by ESF project Nr. 2009/0230/1DP/1.1.1.2.0/09/APIA/VIAA/070.

\section{Address:}

Arnis Abolins

Institute of Oncology, Riga Stradins University, Dzirciema Street 16, Riga, LV-1007, Latvia

E-mail: arnis.abolinsh@inbox.lv

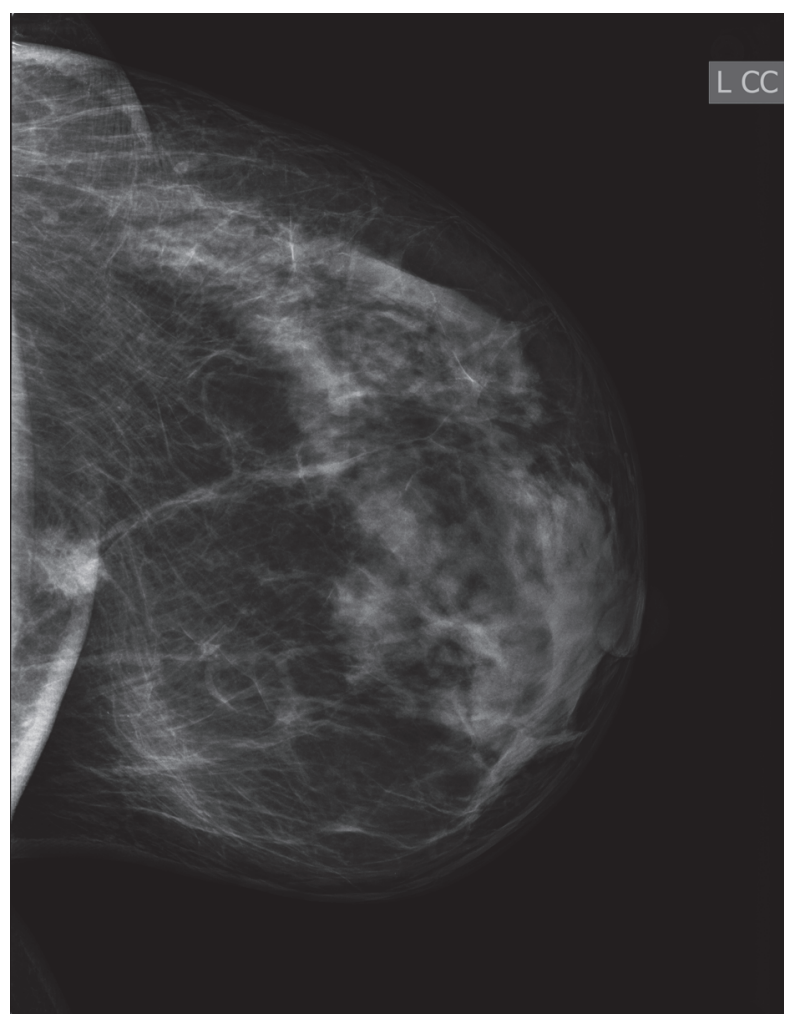

Fig. 1. Mammography of the left breast. Note the stellate focus. 


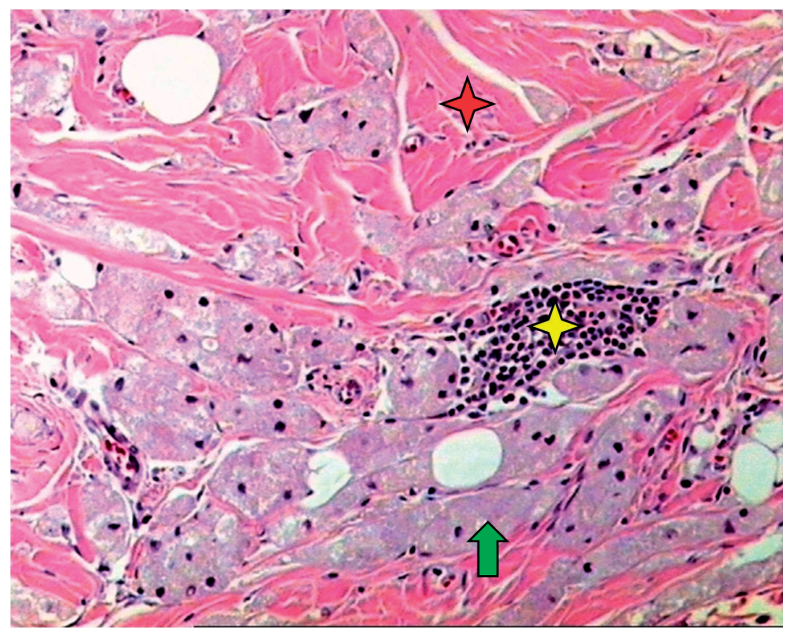

Fig. 2. Microscopic structure of the neoplasm, typical for granular cell tumour. Note the large, bland tumour cells (arrow), desmoplastic stroma (red star) and small group of lymphocytes (yellow star). Haematoxylin-eosin, original magnification 100x.

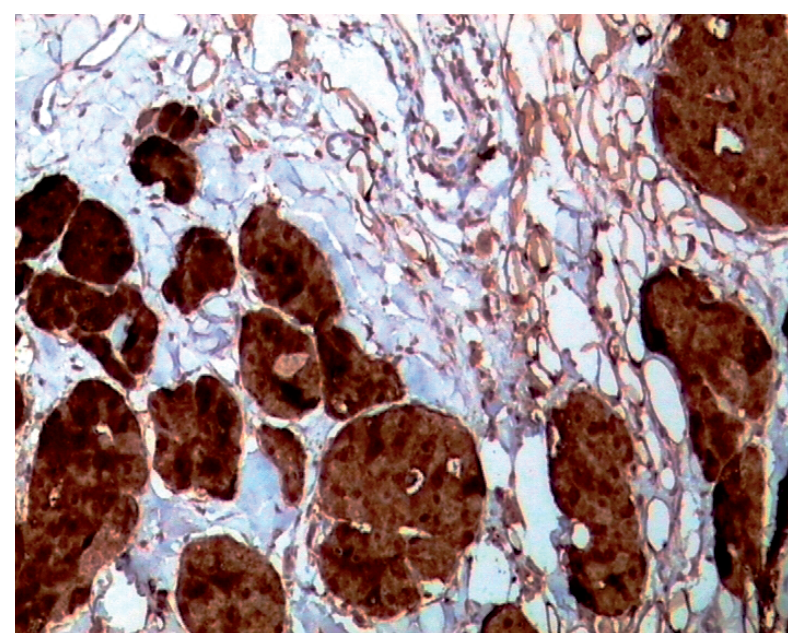

Fig. 3. S-100 protein expression in the tumour cells. Immunoperoxidase, anti-S-100, original magnification 100x. 